\title{
Metabolic Syndrome Response to Different Physical - Exercise Protocols
}

\author{
Mariana Santoro Nakagaki ${ }^{1,2, ~ *, ~ H u g o ~ T a d a s h i ~ K a n o ~}{ }^{1,3}$, Roberto Carlos Burini ${ }^{1}$ \\ ${ }^{1}$ Center for Nutritional and Physical Exercise Metabolism, Department of Public Health, UNESP - Sao Paulo State University, School of \\ Medicine, Botucatu, Brazil \\ ${ }^{2}$ Physical Exercise Graduate Joint Program, Londrina and Maringa State Universities, Londrina, Brazil \\ ${ }^{3}$ Pathology Graduate Program, School of Medicine, UNESP - Sao Paulo State University, Botucatu, Brazil
}

Email address:

msantoro16@hotmail.com (M. S. Nakagaki)

${ }^{*}$ Corresponding author

\section{To cite this article:}

Mariana Santoro Nakagaki, Hugo Tadashi Kano, Roberto Carlos Burini. Metabolic Syndrome Response to Different Physical - Exercise Protocols. American Journal of Sports Science. Vol. 7, No. 4, 2019, pp. 182-192. doi: 10.11648/j.ajss.20190704.19

Received: November 9, 2019; Accepted: November 27, 2019; Published: December 4, 2019

\begin{abstract}
Background: Metabolic syndrome (MetS) represents a growing public health problem throughout the world and, making sense with the epigenetic causes of MetS, lifestyle change seems yet, more clinically effective than drugs. Additionally to dietary adequacy, increased physical activity (LiSM) is considered the cornerstone of recommendations for the treatment of MetS. Previously it was found that different types of physical exercises led to different responses in reducing adiposity, hypertension and hyperglycemia. Now we aim to investigate the specific effect of four different physical-exercise protocols on MetS in a defined short time intervention of 10 weeks. Methods: A sample of 302 individuals $(55.5 \pm 10.8$ years) from both genders was taken among (2013-2016) participants of the dynamic cohort "Move for Health" LiSM program. They were evaluated at baseline and after 10 weeks of supervised intervention with protocols of hydrognastics (HYD, aerobic), High Intensity Interval Training (HIT), resistance training in gym (GYM) and mixed walking-gym (MIX, 30 min of walking 60-80\% HRmax and resistance). All groups received the same basic LiSM dietary counseling. The evaluation instruments were: International Physical Activity Questionnaire (IPAQ-long form-version 8); Healthy Eating Index (HEI), anthropometric, plasma biochemical analyses and physical fitness (flexibility, handgrip strength and treadmill cardiorespiratory capacity). MetS was diagnosed according to NCEP-ATP III (2005). The data were evaluated in continuous and categorized forms. Multiple comparison (moment versus protocol) was undertaken at the level of significance of 5\%. Results: After 10-wk intervention, all protocols incremented the baseline fitness of $\mathrm{VO}_{2}$ max; flexibility (except in the HIT); muscle strength (only in GYM and MIX) and also, the level of physical activity in MIX. There was a $16.9 \%$ reduction in MetS, from $25.4 \%$ (HYD) to 12.7\%(MIX), having HIT (21.5\%) and GYM (16.2\%), in between. Hyperglycemia (20.6\%) and hypertension (15.9\%) responded positively to all protocols, while the reduction of abdominal circumference discriminated the effectiveness of MIX and HYD in reducing MetS. Conclusion: At the same duration, prescribed protocols of HYD, HIT, GYM and MIX decreased MetS in different magnitude according to the MetS-component sensitivity to each protocol.
\end{abstract}

Keywords: Metabolic Syndrome, Lifestyle Modification, Physical-exercise Protocols

\section{Background}

Metabolic Syndrome (MetS) is a complex of abnormalities including abdominal obesity, insulin resistance, atherogenic dyslipidemia and arterial hypertension [1]. Its carriers are twice as likely to develop cardiovascular disease (CVD) and up to five times more likely in type 2 diabetes mellitus (T2D)
[2-4]. Historically, MetS started related to insulin resistance and, subsequently, associated with obesity, with abdominal adiposity being its main component [5]. Today, MetS represents a growing public health problem throughout the world in parallel with the increasing prevalence of diabetes and obesity [6].

The development of MetS may be influenced by genetic as well as environmental factors related to unhealthy body 
composition [7]. The predominant environmental/ behavioral risk factors associated with MetS include obesogenic atherogenic diets, and physical inactivity [8, 9]. Hence, inadequate diet and physical inactivity appeared to be the primary causative factor in the pathogenesis of MetS [7] even though, dietary pattern [10] and food intake seems more related to components rather than the MetS prevalence itself [7].

In general, therapeutic lifestyle change seems yet, more clinically effective than drugs [7]. Consequently, making sense with the epigenetic causes of MetS, the lifestyle modification focusing on improving dietary quality/ physical activity is the preferred first line treatment for the management of MetS and its components. In this sense, the adherence to the Mediterranean diet pattern is associated with lower MetS prevalence and its progression [7]. Similarly, the Paleolithic diet resulted in greater short-term improvements on MetS components than did guideline-based control diets, particularly in terms of its recommendation to exclude grains, dairy, and nutritional products of industry [7]. Overall, the effectiveness of dietary manipulation is mainly based on low-energy dense diets, such as high dietary fiber intake [11].

Specific responses of some individual MetS components can be obtained by dietary W-3 LCFA supplementation [12].

Additionally to dietary adequacy, increased physical activity is considered the cornerstone of recommendations for the treatment of MetS. Aerobic exercises (and increased cardiorespiratory fitness) seems to be even more effective than strength exercises [7]. However, aerobic interval training, strength training or the combination of both has beneficial effects on physiological abnormalities associated with MetS. Additionally, the combination of physical exercises with changes in diet is more effective than each one alone [7].

In a local lifestyle modification (LiSM) program ("Move for Health") aiming to behavioral reeducation through supervised periodized physical exercises and dietary counseling for the health promotion, the MetS prevalence was reduced from $47 \%$ to $40 \%$ in 20 weeks [13] and, a $12.4 \%$ reduction in 24 weeks of intervention [1]. Additional effect of omega-3 supplementation with 3 grams of fish oil on the LiSM program, led to a $29 \%$ reduction in MetS after 20 weeks [14] and, dietary adequacy of fiber ( $25 \mathrm{~g} /$ day) led a $24 \%$ decreasing of MetS just after 10-week of LiSM [15].

As physical exercise intervention, is concern, it was found that different physical exercises such as hydrogimnastics, HIT, walking-jogging, strength and combined (walking and strength) resulted, in a time-dependent manner, in specific responses on the MetS components, hypertension [16] and plasma glucose [17]. Now, we intend to analyze the effect of different physical-exercise protocols (hydrogymnastic, highinterval training, gym and mixed) on MetS in a defined short time intervention of 10 weeks.

\section{Methods}

Participants were enrolled at the "Move for Health Program” (Programa Mexa-se Pró-Saúde), an ongoing epidemiological project conducted, as extension-assistance of the university, since 1991. As described elsewhere, the program introduces healthy lifestyle into subject's diary activities by promoting nutritional re-education and supervised physical exercise as primary care for chronic noncommunicable diseases (obesity, hypertension, T2D and MetS). Individuals spontaneously seek the project and, once enrolled, they are evaluated clinically, contemplating all possible contraindications for physical exercise practice. Anthropometric, dietary, blood biochemistry and physical fitness assessments (strength, flexibility and aerobic endurance) are performed sequentially.

The convenience sample consisted of 302 subjects selected from the period of 2013-2016. From the inclusion criteria, were included data from males and females, 35 years of age or older, physically independent that had a $70 \%$ minimum frequency in physical exercise protocols and attended at the both evaluation moments. All patients were informed about the proposal and procedures to be performed and signed up the informed consent form, in accordance with Resolution 466/2012 of December 12, 2012 of the Ethics in Research Committee (CEP/UEL) under $\mathrm{n}^{\circ} 2,150,766$.

Physical activity level (PAL), socio-demographic characteristics (gender, age, marital status, family income and education) and health status were obtained by applying the International Physical Activity Questionnaire (IPAQ version 8 - long form) [18]. Marital status was classified as married (married and stable union) and unmarried (single, widowed, divorced, and separated). The schooling was ranked as fundamental complete and incomplete, secondary education and higher levels. Family income ranked from up to five minimum wages $(<5 \mathrm{SM})$ or greater/equal to five times the minimum wage $(\geq 5 \mathrm{SM})$. The health perception was rated as good (excellent, very good or good) or bad (fair and poor). The recommended PAL was at least 150 minutes per week of moderate aerobic physical activity or 75 minutes of vigorous aerobic physical activity in the week [19].

The dietary quality was evaluated by the Adapted Healthy Eating Index (HEI) based on the adapted Brazilian Food Pyramid [20]. For the score of this index, the eight food groups of the pyramid, the percentage of total fat, saturated fat, amount of dietary cholesterol and the variety of the diet (represented by the serving of different foods consumed during the day).

The anthropometric evaluation was composed by the measures of body weight and height, according to the procedures described by Heyward and Stolarczyk [21] with a subsequent calculation of the Body Mass Index (BMI = $\mathrm{kg} / \mathrm{m}^{2}$ ) classified according to WHO [22]. Waist circumference (WC) was measured on the midpoint between the last intercostal space and iliac crest [21]. As an indicator of abdominal obesity WC was adopted greater than or equal to $88 \mathrm{~cm}$ for women and $102 \mathrm{~cm}$ for men [23].

Blood pressure (BP) was assessed by using a manual sphygmomanometer, following the recommendations of the VII Brazilian Guideline for Hypertension [24]. Systemic arterial hypertension was defined as pressure levels greater 
than $130 / 85 \mathrm{mmHg}[23,25]$.

To perform the biochemical analysis, the subjects were submitted to blood collection after nocturnal fasting ( 8 to 12 hours), by means of standard vacuum venous puncture. Concentrations of fasting glucose, triglycerides (TG), and HDL cholesterol (HDL-c) were quantified in the serum by the Dry Chemistry method (Vitros, Johnson and Johnson System). The normality classification followed the criteria of NCEP-ATPIII [23, 25]. Metabolic Syndrome was diagnosed when a minimum of 3 from its 5 components were altered, following the National Cholesterol Program's Adult Treatment Panel III (NCEP-ATP III) [23, 26].

Physical fitness was evaluated through trunk flexibility (FLEX), upper limb strength and cardiorespiratory tests. The FLEX was evaluated by using the sit and reach test, following the normal values established by Johnson and Nelson [27]. Muscle strength of upper limbs was determined using the handgrip test with a hydraulic dynamometer with a scale of 0 to $100 \mathrm{~kg}$, following the classification proposed by Baumgartner and Jackson [28]. Cardiorespiratory fitness was determined by maximal oxygen uptake $\left(\mathrm{VO}_{2} \mathrm{max}\right)$ obtained on an electric treadmill (model QMCTM90) using the Balke protocol [29], with constant monitoring of heart rate and blood pressure. The inclination of the treadmill was used to determine the $\mathrm{VO}_{2} \max$. by the formula: $\mathrm{VO}_{2} \max =8.8+(1.8$ * slope) +3.5. After obtaining the $\mathrm{VO}_{2} \max$., the cardiorespiratory fitness was classified following the values established by the AHA [30].

Subjects choose one of four protocols: hydrogymnastics (HYD), high-intensity interval training (HIT), strength training (GYM) and Mixed walking-strength (MIX). All protocols lasted ten weeks and were supervised by qualified professionals and, during that period there was no prescription of diets, only nutritional counseling. Table 1 has the specificities of each protocol.

Table 1. Characteristics of physical exercise protocols applied during a 10-week intervention.

\begin{tabular}{lllll}
\hline Protocols & HYD $(\mathbf{n}=\mathbf{6 3})$ & HIT $(\mathbf{n}=\mathbf{4 3})$ & GYM $(\mathbf{n}=\mathbf{5 0})$ & MIX $(\mathbf{n}=\mathbf{1 4 6})$ \\
\hline Duration (minutes) & 60 & 60 & 60 & 90 \\
Frequency (day/week) & 2 & 2 & 3 & 3 \\
Intensity & Moderate & Moderate/ Vigorous & Moderate & Moderate \\
Total Volume (minutes/week) & 120 & 120 & 180 & 270 \\
Energy expenditure (METs/session)* & 200 & 248,1 & 272,5 & 371,5 \\
\hline
\end{tabular}

* Based on Ainsworth's compendium of physical activity (2000); METs: metabolic equivalent; HYD: hydrogymnastics protocol; HIT: high intensity interval training; GYM: strength protocol; MIX: mixed walking strength.

The hydrogymnastics protocol (HYD) was performed twice a week on alternate days in a 60 minutes session of aerobic/water-based training in pool with water temperature ranging between $27^{\circ} \mathrm{C}$ and $28^{\circ} \mathrm{C}$. Subjects performed 10 minutes of general warm-up, 10 minutes of stretching, 30 minutes of main part (aerobic exercises and located for upper and lower limbs), and 10 minutes of calm/relaxation.

The 60min. sessions of High Intensity Interval Training (HIT) were performed in twice-alternated days, a week. The program of aerobic interval exercise on treadmill was performed according to the protocol of Stensvold et al. [9]. The $43 \mathrm{~min}$. session was distributed in 10 minutes of warmup at $70 \%$ of maximum heart rate (HRmax), followed by 4 sets of 4 minutes to $90 \%$ of HRmax. interspersed with 3minute intervals of active recovery at $70 \%$ of HRmax., finishing with 5 minutes of calm back. The training sessions contained initial stretches (5 minutes) and final stretches (10 minutes), the latter being intended for relaxation and recovery of heart rate. For training prescription it was used the HRmax. obtained by the cardiorespiratory test.

The Gym Protocol (GYM) was performed three times a week on alternate days, constituting resistance training with free weights and machines. The $60 \mathrm{~min}$. session was composed by 10 minutes of warm-up/ dynamic stretching, 40 minutes of resistance training ( 3 sets of 8 to 12 repetitions of 60 to $70 \%$ of a maximal repetition (1RM), and 10 minutes of final stretching. The exercises were performed in the form of a circuit, always alternating between lower and upper limbs, prioritizing first the larger and later smaller muscle groups.
The exercises were leg press, extensor and flexor chair, adductor and abductor chair, calf, bench press, crucifix, paddling, high pull, direct threading, triceps and abdominals (primarily the rectum).

The Mixed Protocol (MIX) was performed three days a week, constituting $90 \mathrm{~min}$. session of combined aerobic and resistance training. Subjects underwent 10 minutes of general warm-up associated with dynamic stretching, 30 minutes of walking (60 to $80 \%$ of the HRmax-controlled by frequency), 40 minutes of resistance training ( 3 sets of 8 to 12 repetitions of 60 to $70 \%$ of $1 \mathrm{RM}$ ) - being the same exercises of the GYM, and 10 minutes of final stretching. The first two weeks were to familiarize the protocol for the subsequent 1RM test, and for the prescription of aerobic training. The maximum heart rate (HRmax) obtained during the exercise test was used for the prescription of MIX.

All data were submitted to analysis of normal distribution pattern using the Kolmogorov Smirnov test. The descriptive analysis contemplates the characterization of the individuals using mean and standard deviation for the continuous variables and frequency and percentage for the categorical variables. The chi-square test of trend for comparison between moments (M0 and M1) for categorized variables was used. For the quantitative variables, the model was used in repeated measurements considering two moments (M0 and M1) and four protocols (GYM, HYD, HIT and MIX) and their interactions. In the case of data with symmetrical distribution - ANOVA followed by post hoc Tukey. In the case of asymmetric data, adjustment was performed in the 
gamma distribution followed by the Wald multiple comparison test, always in the moment versus protocol interaction. The program used was SAS for Windows version 9.3 with significance level of $5 \%$ or corresponding $p$-value.

\section{Results}

The sample consisted of 302 subjects (HYD: 63, HIT: 43, GYM: 50, MIX: 146) aged $55.5 \pm 10.8$ years, $65 \%$ below sixties years, majorly females (88\%), married $(80 \%), 80 \%$ presenting up to elementary-school grade and living under 5 minimum wages (92\%). They mostly referred fed low-quality diet (95\%) and 91\% with adequate physical activity (at least $150 \mathrm{~min} / \mathrm{wk}$ ). In general, they showed good cardiorespiratory fitness (63\%), good strength $(78 \%)$ but poor flexibility $(73 \%)$. Although selfreporting in good health $(67.8 \%), 80.5 \%$ were overweight and $48.7 \%$ with MetS. The altered components were WC $(72.9 \%)$, followed by fasting glycemia $(49 \%)$, BP $(41.4 \%)$, HDL-c (40.5\%) and TG (37.9\%).

The fact that mostly of the sample were females, below sixties living on low-income status, was homogenous in all protocol-groups. Additionally, groups were also similar, in all demographic, socioeconomic, dietary, physical activity and fitness, anthropometric parameters, as well as for MetS prevalence (Table 2).

Table 2. Demographic, socioeconomic, nutritional, anthropometric, fitness and physical activity levels and metabolic syndrome of adult participants in a LiSM program - "Move for Health".

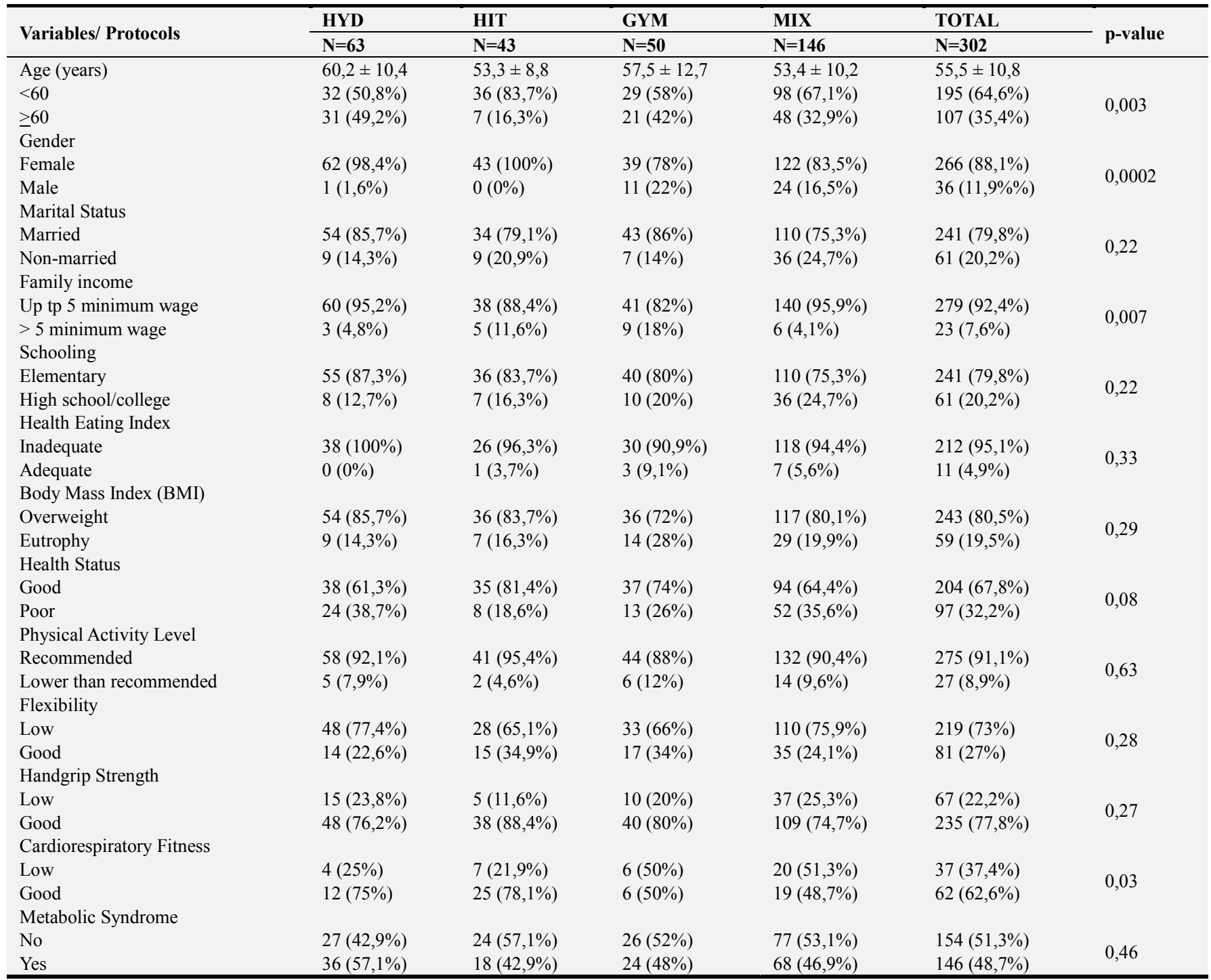

After 10 weeks of intervention, only MIX resulted in a significant increase in weekly physical activity (PA). However, all 4 protocols increased aerobic capacity (treadmill time and $\mathrm{VO}_{2} \mathrm{max}$ ). Flexibility responded to the HYD, GYM and MIX, as did the strength to the GYM and
MIX. In general, the observed variations between protocols were significant only for PA (IPAQ). It is not worthy that MIX started from lower baseline values and, after intervention (M1) reached a similar value regarded those from the other protocols (Table 3). 
Table 3. Effect of 10 weeks of intervention on activity level and physical fitness in different physical exercise protocols of adults participating in a LiSM program - "Move for Health".

\begin{tabular}{|c|c|c|c|c|c|c|}
\hline \multirow{2}{*}{ Variables } & \multirow{2}{*}{ Moment } & \multicolumn{4}{|l|}{ Protocols } & \multirow{2}{*}{ p-value } \\
\hline & & HYD & HIT & GYM & MIX & \\
\hline \multirow{2}{*}{ Flexibility (cm) } & M0 & $20,1 \pm 8,2 \mathrm{aA}$ & $25,1 \pm 9,0 \mathrm{aB}$ & $22,8 \pm 10,9 \mathrm{aAB}$ & $21,5 \pm 8,4 \mathrm{aA}$ & \multirow{2}{*}{0,41} \\
\hline & M1 & $21,9 \pm 8,3 \mathrm{bA}$ & $27,5 \pm 8,5 \mathrm{aB}$ & $24,5 \pm 10,6 \mathrm{bAB}$ & $24,2 \pm 8,4 \mathrm{bAB}$ & \\
\hline \multirow{2}{*}{ Handgrip Strength (kg) } & M0 & $26,1 \pm 6,5 \mathrm{aB}$ & $29,5 \pm 6,0 \mathrm{aA}$ & $31,7 \pm 12,9$ aA & $29,6 \pm 10,6 \mathrm{aA}$ & \multirow{2}{*}{0,01} \\
\hline & M1 & $26,4 \pm 6,7 \mathrm{aB}$ & $29,9 \pm 5,9 \mathrm{aC}$ & $34,6 \pm 13,3 \mathrm{bA}$ & $31,2 \pm 10,0 \mathrm{bAC}$ & \\
\hline \multirow{2}{*}{ Test Time (sec.) } & M0 & $489,7 \pm 166,6 \mathrm{aA}$ & $640,6 \pm 184,1 \mathrm{aB}$ & $627,0 \pm 312,3 \mathrm{aAB}$ & $559,7 \pm 192,6 \mathrm{aAB}$ & \multirow{2}{*}{0,41} \\
\hline & M1 & $643,3 \pm 165,3 \mathrm{bA}$ & $809,5 \pm 202,4 \mathrm{bB}$ & $737,5 \pm 333,2 \mathrm{bAB}$ & $674,9 \pm 206,0 \mathrm{bA}$ & \\
\hline \multirow{2}{*}{$\mathrm{VO}_{2}$ máx $(\mathrm{ml} / \mathrm{kg} / \mathrm{min})$} & M0 & $27,9 \pm 5,2 \mathrm{aA}$ & $32,3 \pm 5,4 \mathrm{aB}$ & $31,8 \pm 8,9 \mathrm{aAB}$ & $29,9 \pm 5,9 \mathrm{aAB}$ & \multirow{2}{*}{0,42} \\
\hline & M1 & $32,7 \pm 4,9 \mathrm{bA}$ & $37,2 \pm 5,9 \mathrm{bB}$ & $35,1 \pm 9,2 \mathrm{bAB}$ & $33,5 \pm 6,2 \mathrm{bA}$ & \\
\hline \multirow{2}{*}{ Physical Activity (min/week) } & M0 & $831,1 \pm 721,4 \mathrm{aA}$ & $889,8 \pm 707,9 \mathrm{aA}$ & $839,5 \pm 720,4 \mathrm{aA}$ & $586,1 \pm 469,7 \mathrm{aB}$ & \multirow{2}{*}{$<0,0001$} \\
\hline & M1 & $976,9 \pm 799,2 \mathrm{aA}$ & $960,4 \pm 697,4 \mathrm{aA}$ & $750,4 \pm 499,3 \mathrm{aA}$ & $940,3 \pm 660,4 \mathrm{bA}$ & \\
\hline
\end{tabular}

Lowercase letters: difference between moments; capital letters: difference between protocols; $p<0.05$ (moment-to-protocol interaction).

There was no change in HEI due to the different protocols, though; all remained unsatisfactory (below 100 points). Considering each protocol, it is observed that: GYM increased weight and consequently BMI, but this gain was related more to muscle mass rather than body fat.
HYD significantly reduced body fat and HIT gained fat free mass. However, comparing the anthropometric changes among protocols, it was concluded that the intervention did not alter significantly the indicators (Table 4).

Table 4. Effect of 10 weeks of intervention on the anthropometric, body composition and nutritional variables in different protocols of physical exercises of adults participating in a LiSM program - "Move for Health".

\begin{tabular}{|c|c|c|c|c|c|c|}
\hline \multirow{2}{*}{ Variables } & \multirow{2}{*}{ Moment } & \multicolumn{4}{|l|}{ Protocols } & \multirow{2}{*}{ p-value } \\
\hline & & HYD & HIT & GYM & MIX & \\
\hline Weight (kg) & M0 & $76,9 \pm 14,7 \mathrm{aA}$ & $75,5 \pm 14,6 \mathrm{aA}$ & $76,8 \pm 17,2 \mathrm{aA}$ & $78,3 \pm 17,6 \mathrm{aA}$ & 0,11 \\
\hline \multirow{2}{*}{ Body Mass Index $\left(\mathrm{kg} / \mathrm{m}^{2}\right)$} & M0 & $31,6 \pm 6,1 \mathrm{aA}$ & $29,4 \pm 6,5 \mathrm{aB}$ & $29,7 \pm 5,7 \mathrm{aAB}$ & $30,2 \pm 6,1 \mathrm{aAB}$ & \multirow{2}{*}{0,45} \\
\hline & M1 & $31,3 \pm 6,1 \mathrm{aA}$ & $30,3 \pm 4,7 \mathrm{aA}$ & $30,1 \pm 5,9 \mathrm{bA}$ & $29,9 \pm 6,0 \mathrm{aA}$ & \\
\hline Fat Free Mass (kg) & M0 & $45,4 \pm 4,9 \mathrm{aB}$ & $46,8 \pm 4,6 \mathrm{aAB}$ & $49,4 \pm 10 \mathrm{aAC}$ & $49,7 \pm 8,8 \mathrm{aC}$ & 0,29 \\
\hline \multirow{2}{*}{ Body Fat (\%) } & M0 & $39,6 \pm 8,4 \mathrm{aB}$ & $36,9 \pm 8,1 \mathrm{aAB}$ & $35,1 \pm 9,6 \mathrm{aA}$ & $35,5 \pm 9,0 \mathrm{aA}$ & \multirow{2}{*}{0,16} \\
\hline & M1 & $38,5 \pm 8,9 \mathrm{bB}$ & $37,4 \pm 8,1 \mathrm{aAB}$ & $34,6 \pm 9,2 \mathrm{aA}$ & $35,4 \pm 8,9 \mathrm{aA}$ & \\
\hline \multirow{2}{*}{ Muscle Mass (kg) } & M0 & $18,9 \pm 3,3 \mathrm{aB}$ & $20,8 \pm 4,2 \mathrm{aA}$ & $21,1 \pm 5,8 \mathrm{aA}$ & $21,7 \pm 5,7 \mathrm{aA}$ & \multirow{2}{*}{0,06} \\
\hline & M1 & $18,5 \pm 2,6 \mathrm{aB}$ & $21,1 \pm 4,3 \mathrm{aA}$ & $21,7 \pm 6,2 \mathrm{bA}$ & $21,6 \pm 5,4 \mathrm{aA}$ & \\
\hline \multirow{2}{*}{ Muscle Mass (\%) } & M0 & $25,1 \pm 4 \mathrm{aB}$ & $26,9 \pm 4,3 \mathrm{aA}$ & $27,6 \pm 4,6 \mathrm{aA}$ & $27,9 \pm 5,3 \mathrm{aA}$ & \multirow{2}{*}{0,43} \\
\hline & M1 & $24,8 \pm 3,5 \mathrm{aB}$ & $26,6 \pm 4,3 \mathrm{aA}$ & $27,9 \pm 5,3 \mathrm{aA}$ & $28,1 \pm 5,2 \mathrm{aA}$ & \\
\hline Muscle Mass Index $\left(\mathrm{kg} / \mathrm{m}^{2}\right)$ & M1 & $7,6 \pm 0,9 \mathrm{aA}$ & $8,5 \pm 2,3 \mathrm{aB}$ & $8,3 \pm 1,7 \mathrm{bAB}$ & $8,3 \pm 1,5 \mathrm{aB}$ & 0,10 \\
\hline \multirow{2}{*}{ Abdominal Sagital Diameter $(\mathrm{cm})$} & M0 & $23,4 \pm 3,7 \mathrm{aA}$ & $22,1 \pm 3,3 \mathrm{aA}$ & $22,3 \pm 3,9 \mathrm{aA}$ & $22,7 \pm 3,7 \mathrm{aA}$ & \multirow{2}{*}{0,62} \\
\hline & M1 & $23,1 \pm 3,6 \mathrm{aA}$ & $22,2 \pm 3,4 \mathrm{aA}$ & $21,9 \pm 3,6 \mathrm{aA}$ & $22,5 \pm 3,5 \mathrm{aA}$ & \\
\hline \multirow{2}{*}{ Healthy Eating Index (points) } & M0 & $75,5 \pm 11,9 \mathrm{aB}$ & $75,9 \pm 12,7 \mathrm{aAB}$ & $81,5 \pm 13,8 \mathrm{aAC}$ & $81,5 \pm 12,9 \mathrm{aC}$ & \multirow{2}{*}{0,33} \\
\hline & M1 & $77,7 \pm 11,9 \mathrm{aA}$ & $77,6 \pm 12,3 \mathrm{aA}$ & $77,5 \pm 11,9 \mathrm{aA}$ & $80,9 \pm 10,9 \mathrm{aA}$ & \\
\hline
\end{tabular}

Lowercase letters: difference between moments; capital letters: difference between protocols; $\mathrm{p}<0.05$ (moment-to-protocol interaction).

After intervention, there was an averaged reduction of $16.9 \%$ in MetS, statistically significant in HYD (25.4\%) and MIX (12.7\%). Not standing the fact that, the reduction of the number of altered MetS components, was similar in all protocols, specifically the decreasing of $\mathrm{WC}$ happened in HYD, GYM and MIX, with the observed decreasing in MIX, being significantly higher than HYD and HIT (Table 5).

Reduction of fasting glucose occurred in all protocols except GYM. SBP reduced in HYD and both, SBP and DBP, in MIX, but without difference between post-intervention protocols. The plasma TG was reduced only in GYM (Table $5)$.

Table 5. Effect of 10 weeks of intervention on the components of the Metabolic Syndrome in different physical exercise protocols of adults participating in a LiSM program - "Move for Health".

\begin{tabular}{|c|c|c|c|c|c|c|}
\hline \multirow{2}{*}{ Variables } & \multirow{2}{*}{ Moment } & \multicolumn{4}{|l|}{ Protocols } & \multirow{2}{*}{ p-value } \\
\hline & & HYD & HIT & GYM & MIX & \\
\hline \multirow{2}{*}{ Waist Circumference $(\mathrm{cm})$} & M0 & $102,6 \pm 13,7 \mathrm{aA}$ & $95,5 \pm 11,5 \mathrm{aB}$ & $99,8 \pm 14,4 \mathrm{aAB}$ & $99,8 \pm 14,7 \mathrm{aAB}$ & \multirow{2}{*}{0,03} \\
\hline & M1 & $101,3 \pm 13,1 \mathrm{bA}$ & $95,7 \pm 11,6 \mathrm{aB}$ & $97,6 \pm 13,7 \mathrm{bAB}$ & $97,7 \pm 13,5 \mathrm{bAB}$ & \\
\hline \multirow{2}{*}{ Triglycerides (mg/dL) } & M0 & $137,9 \pm 47,4 \mathrm{aA}$ & $139,4 \pm 72,5 \mathrm{aA}$ & $153,8 \pm 63,4 \mathrm{aA}$ & $144,0 \pm 79,6 \mathrm{aA}$ & \multirow{2}{*}{0,22} \\
\hline & M1 & $139 \pm 50,4 \mathrm{aA}$ & $138,0 \pm 71,9 \mathrm{aA}$ & $134,6 \pm 63,5 \mathrm{bA}$ & $144,4 \pm 84,1 \mathrm{aA}$ & \\
\hline
\end{tabular}




\begin{tabular}{|c|c|c|c|c|c|c|}
\hline \multirow{2}{*}{ Variables } & \multirow{2}{*}{ Moment } & \multicolumn{4}{|l|}{ Protocols } & \multirow{2}{*}{ p-value } \\
\hline & & HYD & HIT & GYM & MIX & \\
\hline \multirow{2}{*}{ HDL-c (mg/dL) } & M0 & $52,3 \pm 10 \mathrm{aA}$ & $51,3 \pm 12,8 \mathrm{aA}$ & $50,9 \pm 11,7 \mathrm{aA}$ & $54,7 \pm 12,9 \mathrm{aA}$ & \multirow{2}{*}{0,44} \\
\hline & M1 & $52,5 \pm 10,3 \mathrm{aA}$ & $53,8 \pm 12,6 \mathrm{aA}$ & $51,5 \pm 12,4 \mathrm{aA}$ & $53,9 \pm 13,3 \mathrm{aA}$ & \\
\hline \multirow{2}{*}{ Systolic Blood Pressure (mmHg) } & M0 & $127,6 \pm 16,5 \mathrm{aA}$ & $117,6 \pm 12,9 \mathrm{aB}$ & $121,9 \pm 15 \mathrm{aABC}$ & $122,6 \pm 17,4 \mathrm{aC}$ & \multirow{2}{*}{0,11} \\
\hline & M1 & $121,2 \pm 17,9 \mathrm{bA}$ & $118,2 \pm 14,8 \mathrm{aA}$ & $120,1 \pm 16,8 \mathrm{aA}$ & $120,0 \pm 15,3 \mathrm{bA}$ & \\
\hline \multirow{2}{*}{ Diastolic Blood Pressure (mmHg) } & M0 & $80,4 \pm 11,1 \mathrm{aA}$ & $74,8 \pm 11,7 \mathrm{aB}$ & $77,9 \pm 10,6 \mathrm{aAB}$ & $78,4 \pm 11,6 \mathrm{aAB}$ & \multirow{2}{*}{0,24} \\
\hline & M1 & $79,1 \pm 13,2 \mathrm{aA}$ & $75,7 \pm 11,7 \mathrm{aAB}$ & $76,3 \pm 11,1 \mathrm{aAB}$ & $75,6 \pm 10,1 \mathrm{bB}$ & \\
\hline \multirow{2}{*}{ Fasting Glucose (mg/dL) } & M0 & $106,5 \pm 26,8 \mathrm{aAB}$ & $99,4 \pm 21,7 \mathrm{aB}$ & $115,8 \pm 52,4 \mathrm{aA}$ & $110,7 \pm 38,9 \mathrm{aA}$ & \multirow{2}{*}{0,78} \\
\hline & M1 & $95,5 \pm 14,4 \mathrm{bA}$ & $91,6 \pm 18,9 \mathrm{bA}$ & $102,6 \pm 39,8 \mathrm{aAB}$ & $101,9 \pm 23,9 \mathrm{bB}$ & \\
\hline \multirow{2}{*}{ Altered Components (numbers) } & M0 & $2,6 \pm 1,1 \mathrm{aA}$ & $2,1 \pm 1,3 \mathrm{aB}$ & $2,4 \pm 1,4 \mathrm{aAB}$ & $2,4 \pm 1,3 \mathrm{aAB}$ & \multirow{2}{*}{0,34} \\
\hline & M1 & $1,7 \pm 0,9 \mathrm{bA}$ & $1,4 \pm 1,0 \mathrm{bA}$ & $1,6 \pm 1,3 \mathrm{bA}$ & $1,8 \pm 1,4 \mathrm{bA}$ & \\
\hline
\end{tabular}

Lowercase letters: difference between moments; capital letters: difference between protocols; $\mathrm{p}<0.05$ (moment-to-protocol interaction).

Hence, except for WC, the reductions of other components occurred at similar intensities between the protocols. The components of MetS most responsive to the protocols were hyperglycemia (20.6\%) and hypertension (15.9\%). Hypertension responded significantly to HYD (25.3\%), GYM (18\%) and MIX (16.5\%), and glycemia to HIT (29.8\%), GYM (22.7\%) and MIX (19.2\%) (Table 5).

Thus, the decreasing of MetS was found in all protocols, generally by reducing fasting glucose and blood pressure. For doing that, more effectively, HYD and HIT were the best protocols. MIX-related WC reduction made this protocol more effective than HYD, however in a long-lasting session manner.

\section{Discussion}

This spontaneously assembled sample was predominantly female, with characteristics of low schooling and income, taking habitually a monotonously low quality diet. They referred be accomplishing the WHO's recommended level of PA (minimum 150min./wk) even though the assessed fitness detected poor trunk flexibility along with fair good arm strength and aerobic capacity. Although referring in good health status, $4 / 5$ were overweight with MetS being present in $48.7 \%$ of the sample.

In our previous studies MetS varied from $28 \%$ to $51 \%$ [7] and, similarly to the present data, MetS was commonly found among low schooling and low-income individuals, presenting a lower physical activity level. The ingested poor quality diet was characterized by low intake of fiber, fruit, vegetables and whole grains and, on other hand, high intake of sugar, refined grains, cholesterol and vegetable oil [1].

Besides diet, both, physical activity (PA) and fitness play key roles in the prevention and treatment of MetS [1, 7]. Studies [31-34] clearly demonstrate the pathogenesis of MetS largely attributable to aptitude and PA. In the present study, $91 \%$ of the sample reported to be under the recommended PA (150 minutes per week), even though half of them (48.7\%) presented MetS! The apparent conflict between data may be due to the fact that the PA was obtained through self-report (questionnaire), and may overestimate the PA of these individuals, specifically in domestic PA, once the majority were "housewives" women.

Energy expenditure through PA is difficult to assess accurately because it is based on self-reported data. Even so, they are the ideal measure by assessing risk, and therefore useful in evaluating large datasets [35]. Being low-income, the majority of the sample probably spent greater energy in their labor and transportation domains, decreasing the energy expenditure with leisure [36]. Hence, leisure programs such as "Move for Health" make differences in the weekly daily energy expenditure [37]. More coherent, than IPAQ, for the high prevalence of MetS, were the physical fitness showing $73 \%$ of poor flexibility, $37.4 \%$ poor cardiorespiratory fitness and $22.2 \%$ poor strength. These data were much more in agreement also with the prevalence of overweight in $80.5 \%$ of the sample.

Dietary intervention has a prominent effect on MetS [3840]. Previous data [1, 7, 11] and other studies [41-47] have suggested that combined interventions involving diet and exercise were more effective in the treatment and prevention of MetS. The present study was not designed for specific dietary interventions, unless the common counseling of the Move for Health program [48], consequently there was no changes in HEI in the different exercise protocols.

Hyperadiposity, particularly abdominal, is known as very important for diagnosis and evolution of MetS [1, 7]. According to Sasayama et al. [49] the score in the risk for MetS of the high BMI/ high physical fitness group was significantly lower than the BMI high/low physical fitness group in both genders, which evidences the importance of physical fitness in relation to improvement of body composition. A study with obese patients reported a greater decrease in body weight with moderate walking compared to high intensity interval training (HIT) [50]. On the other hand, two other studies did not obtain improvements, postintervention, between the HIT groups and moderate walking, for weight loss, BMI or body composition [51, 52]. In the long run, there is evidence that HIT may lead to further reductions in abdominal fat mass [53] and increased muscle mass [54]. Presently, after 10wk-intervention, the decrease in body fat occurred only in the HYD, and probably, by the fact that it started from higher basal values than the other protocols. HYD not only significantly reduced body fat but also presented the higher decreasing of MetS (25.4\%).

There was a significant improvement of the flexibility in the several protocols offered, with the exception of the HIT. Reduced flexibility was reported as positively associated with the presence of MetS regardless of age, gender, and other measures regarding body composition and physical 
fitness [55].

Cardiorespiratory fitness also has been consistently associated with many components of MetS, including insulin resistance, HDL cholesterol, TG and BP levels [56]. In this aspect, the present protocols responded similarly, by increasing the aerobic capacity. That is because they were designed to be in a similar aerobic basis. Even the individuals performing the Academy protocol, reported having a complementary regular leisure walk, outside the program. Lakka et al. [31] observed associations of leisure-time PA and cardiorespiratory fitness with MetS. Men who engaged in moderate-intensity leisure PA, 1h/week or less were $60 \%$ more likely to have MetS than those engaging in $3 \mathrm{~h} /$ week or more. In addition, men with $\mathrm{VO} 2$ max. equal to or less than $29.1 \mathrm{~mL} / \mathrm{kg} / \mathrm{min}$ were approximately seven times more likely to present MetS than those with $\mathrm{VO}_{2}$ max. equal to or greater than $35.5 \mathrm{~mL} / \mathrm{kg} / \mathrm{min}$. In women, the prevalence of MetS was lower, as fitness increased, varying from $19 \%$ in the lower quintile, to $2.3 \%$ in the higher quintile of cardiorespiratory fitness, evaluated by the maximum treadmill test [33].

Katzmarzyk et al. [57] investigated the efficacy of physical training in the treatment of MetS in participants (men and women, aged 17-65 years), with 20 weeks of supervised aerobic training $(3 \mathrm{x} /$ week at $55 \% \mathrm{VO} 2 \mathrm{max}$ for $30 \mathrm{~min}$ and progressing up to $75 \% \mathrm{VO} 2 \mathrm{max}$ for 50 minutes). The prevalence of MetS was $16.9 \%$ (by the NCEP ATP III criteria) and, after 20 weeks of training, $30.5 \%$ of the MetS patients were no longer classified as MetS. In the present study, in half of length (10 wks) the LiSM participants had an improvement in aerobic fitness and, under different PE protocols, presented an averaged $16.9 \%$ reduction in MetS.

Aerobic training reduces the blood pressure of prehypertensive $(2.1 / 1.7 \mathrm{mmHg})$ and hypertensive $(8.3 / 5.2$ $\mathrm{mmHg}$ ), being the preferred form of exercise for essential blood hypertension prevention and treatment [58]. The study by Tjonna et al. [51] showed that both moderate and high intensity exercise were effective in reducing both systolic and diastolic blood pressure.

Several studies have found an increase in insulin sensitivity regardless of changes in body weight and/or body composition. Duncan et al. [59] observed a $40 \%$ increase in insulin sensitivity of adults, previously sedentary after a moderate intensity walking intervention, regardless of any change in BMI or WC. Therefore, aerobic/endurance training is very effective in increasing insulin sensitivity, usually $25 \%$ to $50 \%$ in several age groups and populations, including men $[60,61]$ and women [62] who are overweight [63-65], and first-degree relatives of patients with T2D [66-68] and individuals with T2D [69].

In relation to high intensity interval training, there was a significant improvement in fasting blood glucose in this study. DiPietro et al. [65] were observed in the high-intensity training $\left(\sim 80 \% \quad \mathrm{VO}_{2} \mathrm{max}\right)$ caused an increase in insulin sensitivity $(21 \%)$, regardless of changes in body composition or $\mathrm{VO}_{2}$ max. with the same volume of training.

In a study comparing moderate intensity aerobic training (70\% of HRmax) with high intensity interval training $(90 \%$
HRmax) three times a week, a decrease in the number of MetS components was observed, regardless of differences in body weight, which were similar. Interval training was superior to that of moderate intensity in the improvement of endothelial function, insulin signaling in fat and skeletal muscle, biogenesis of skeletal muscle and reduction of glycaemia and lipogenesis in adipose tissue, which probably contributed to mechanisms underlying beneficial effects of interval training in MetS [51]. Therefore, it can be hypothesized that HIT may lead to increased glucose control when compared to the continuous exercise of moderate intensity commonly prescribed to individuals with impaired glucose tolerance or T2D. However, the present study did not observe such modifications.

Muscle strength and lean body mass are also related to MetS. Atlantis et al. [70] also observed an increase in the prevalence of MetS (by both NCEP-ATP III and IDF criteria) in individuals with low handgrip strength. Presently, the strength responded positively to the GYM and MIX protocols and it is suggested that this happens due to the stimulation of hypertrophy given by both protocols. At the same time, it was observed that GYM increased weight, BMI and IMM, and it is believed that as a consequence of the increase in MM. Jurca et al. [71] demonstrated that higher muscle strength is associated with a lower prevalence of MetS components. They found also that each of the five components of MetS was inversely associated with muscle strength, as determined by the 1RM bench press and leg press test when adjusted for age and smoking.

Regarding the resistance protocol (Academy), it was observed that it was effective in reducing both hypertension and hyperglycemia, in addition to reducing WC and TG. Tomeleri et al. [72] showed that 12 weeks of resistance training was able to significantly reduce blood glucose, WC, and SBP in elderly women. Conceição et al. [73] studied postmenopausal women and also achieved significant reductions in fasting glycaemia after 16 weeks of resistance training (10 exercises, 3x 8-10 maximal repetitions, 3x/week, and improved body composition. On the other hand, Lemes et al. [74] reported that resistance training might help reduce SBP levels in MetS patients, but without effect on other metabolic parameters such as glucose, HDL-c, and TG concentrations.

The mixed protocol (aerobic associated with resistance) led to a $12.7 \%$ MetS reduction, after 10 weeks. Kemmler et al. [75] studied the combined exercise training (4 days/ week), with aerobic exercise (20 min, 70-85\% HRmax) associated with resistance (2 sets, $12-15$ repetitions) in elderly women with MetS. They observed that, although several components of MetS decreased significantly, there was no significant decrease in MetS classified by IDF. Studying the effect of combined protocol on the prevalence of MetS in older individuals (55-75 years), Stewart et al. [76] used exercise protocol three times a week, seven exercises, two sets of 10-15 repetitions in 50\% 1RM and 45 minutes of aerobic exercise at $60-90 \% \mathrm{HRmax}$. There was no significant difference in the number of individuals without MetS in the 
intervention versus control groups, although the number of MetS components decreased with respect to the control group. Previous studies have shown that 10 weeks of combined protocol is effective in reducing insulin resistance $[77,78]$, TG $[79,80]$ and BP [81] in addition to MetS [11].

Similarly to 90min-length session of MIX, a shorter session (60min) of HYD was effective in reducing hypertension, hyperglycemia, and WC.

Thus, Individuals entering the LiSM program present changes in the components of MetS, characteristics of the modern lifestyle, particularly the sedentary one. Although numerous studies have investigated the efficacy of physical exercises on MetS in adults/older adults, there is still a need to better understand the combined and/or isolated response of MetS components to different training protocols. By using a representative sample and a wide range of specific variables the present study adds both theoretical/ conceptual value on the theme and practical implications in the prevention and treatment of MetS. As major practical implication was the choice of protocols according to individual preference.

Considering, for health purposes, that the "best exercise is the one that is enjoyable done", it is believed that from the moment that the individual chooses to enter into a LiSM Program such as "Move for Health" and chooses the type of exercise that wants to do, the chances of this individual to incorporate in their daily life habits by the regular practice of physical exercise, is much greater than if this or that exercise were imposed. Hence, the present study reinforces the benefits of adopting a healthy lifestyle with regular physical exercise to reduce MetS, regardless of the exercise protocol performed in a 10 -week period.

Despite the optimistic findings, the present study had important limitations. The use of specific population in convenience sampling does not allow the generalization of the results. Additionally, the application of a subjective method to assess the level of physical activity (questionnaire - IPAQ), that is, self-report, possibly overestimated the values, mainly in domestic activities because they are majority women, "housewives". Only dietary counseling was performed, without specific interventions, that would bring more effective results. Weight loss could have been optimized if accompanied by diet, which would possibly lead to even more beneficial results of body composition. Finally, the MIX protocol had daily sessions 30min longer than the others, having though important differences in training volume, which may have led to the present result. But anyway, once more it was evident that, longer the moderateexercise practicing, better are the results!

\section{Conclusion}

The sample adherent to LiSM program present changes in the components of MetS, characteristics of the modern lifestyle, particularly the sedentary one. However, when submitted to intervention, they respond with improvement of MetS.

This study reinforces the benefits of adopting a healthy lifestyle, with regular physical exercise, to reduce MetS, regardless of the exercise protocol performed over a 10-week period.

Thus, the "Move for Health" program represents an effective, practical and costless strategy in improving metabolic parameters related to chronic non-communicable diseases. Its effects and positive indications are closely linked to the improved physical fitness obtained by the LiSM intervention.

\section{References}

[1] Burini RC, Michelin E, Burini FHP, Moreto F, McLellan KCP. Behavioral risk factors and effects of lifestylemodification on the metabolic syndrome in adults. A Brazilian community-based study. In: (Org.). ICMLGPAPG, editor. Handbook on Metabolic Syndrome: Classification, Risk Factors and Health Impact. 1. 1ed.: Nova Science Pub Inc. 2012. p. 1-413.

[2] Gami AS, Witt BJ, Howard DE, Erwin PJ, Gami LA, Somers $\mathrm{VK}$, et al. Metabolic syndrome and risk of incident cardiovascular events and death: a systematic review and meta-analysis of longitudinal studies. J Am Coll Cardiol. 2007; 49 (4): 403-14.

[3] Mottillo S, Filion KB, Genest J, Joseph L, Pilote L, Poirier P, et al. The metabolic syndrome and cardiovascular risk a systematic review and meta-analysis. J Am Coll Cardiol. 2010; 56 (14): 1113-32.

[4] Ford ES, Li C, Sattar N. Metabolic syndrome and incident diabetes: current state of the evidence. Diabetes Care. 2008; 31 (9): 1898-904.

[5] Medina WL, Burini FHP, Pereira AF, Burini RC. Síndrome Metabólica. In: Daniel Magnoni; Celso Cukier. (Org.). Perguntas e respostas em nutrição clínica: Sao Paulo: Roca, 2ed. 2004, 171-8.

[6] King H, Aubert RE, Herman WH. Global burden of diabetes, 1995-2025: prevalence, numerical estimates, and projections. Diabetes Care. 1998; 21 (9): 1414-31.

[7] Burini RC, Kano HT, Burini FHP, McLellan KCP. Metabolic Syndrome - From the Mismatched Evolutionary Genome with the Current Obesogenic Environment to the Lifestyle Modification as a Primary Care of Free-Living Adults in a Brazilian Community. In: Morton IJ, editor. Metabolic Syndrome: Clinical Aspects, Management Options and Health Effects. Nova Science Publ. (NY) 2016.

[8] Carnethon MR, Loria CM, Hill JO, Sidney S, Savage PJ, Liu K, et al. Risk factors for the metabolic syndrome: the Coronary Artery Risk Development in Young Adults (CARDIA) study, 1985-2001. Diabetes Care. 2004; 27 (11): 2707-15.

[9] Stensvold D, Tjonna AE, Skaug EA, Aspenes S, Stolen T, Wisloff $U$, et al. Strength training versus aerobic interval training to modify risk factors of metabolic syndrome. J Appl Physiol (1985). 2010; 108 (4): 804-10.

[10] Marsola FC, Rinaldi AEM, Siqueira M, Portero-McLellan KC, Corrente JE, Burini RC. Association of dietary patterns with metabolic syndrome components in low-income, free-living Brazilian adults. International Journal of Nutrition and Metabolism. 2011; 3 (2): 17-21. 
[11] Mecca MS, Moreto F, Burini FH, Dalanesi RC, McLellan KC, Burini RC. Ten-week lifestyle changing program reduces several indicators for metabolic syndrome in overweight adults. Diabetol Metab Syndr. 2012; 4 (1): 1.

[12] Talon LC, Oliveira EP, Moreto F, Portero-McLellan KC, Burini RC. Omega-3 fatty acids supplementation decreases metabolic syndrome prevalence after lifestyle modification program. J Functional Foods 2015; 19: 922-8.

[13] Moreto F, Kano HT, Torezan GA, de Oliveira EP, Manda RM, Teixeira $\mathrm{O}$, et al. Changes in malondialdehyde and C-reactive protein concentrations after lifestyle modification are related to different metabolic syndrome-associated pathophysiological processes. Diabetes Metab Syndr. 2015; 9 (4): 218-22.

[14] de Oliveira EP, Talon LC, Moreto F, Acerra VMR, McLellan KCP, Burini RC. Additional Benefits of W-3 Oil Supplements on Metabolic Syndrome Care in Exercise Protocol Intervention. In: Wilkins PLW, editor.: Medicine and Science In Sports and Exercise; 2012. p. 272.

[15] Goncalves LS, Mecca MS, Burini FHP, Dalanesi RC, Peresi VL, Burini RC. Dietary-fibre Adequacy Potentiates Physical Exercises In Metabolic Syndrome Management. In: 3rd World Congress on Exercise is Medicine; San Francisco: Official Journal of the American College of Sports Medicine; 2012. p. 148 .

[16] Burini RC, Nakagaki MS, Michelin E, Burini FHP. Treating Blood Hypertension in a Brazilian Community: Moving from Reactive Homeostatic Model to Proactive Allostatic Healthcare. Ann Clin Hypertens. 2018; 2: 001-16.

[17] Nakagaki MS, Kano HT, Burini RC. Brazilian Primary Care of T2D with Reactive-Homeostatic and Lifestyle ChangingAllostatic Approaches: A Cost-Effectiveness Data. American Journal of Sports Science. 2018; 6 (3): 98-107.

[18] Craig CL, Marshall AL, Sjostrom M, Bauman AE, Booth ML, Ainsworth BE, et al. International physical activity questionnaire: 12-country reliability and validity. Med Sci Sports Exerc. 2003; 35 (8): 1381-95.

[19] World Health Organization (WHO). Global Recommendations on Physical Activity for Health. Geneva (Switzerland): WHO Press. 2010: 24-6.

[20] Mota JF, Rinaldi AEM, Pereira AF, Maestá N, Scarpin MM, Burini RC. Adaptação do índice de alimentação saudável ao guia alimentar da população brasileira. Revista de Nutrição. 2008; $21: 545-52$.

[21] Heyward V, Stolarczyk L. Avaliação da composição corporal aplicada. 1 edition São Paulo. 2000.

[22] World Health Organization (WHO). OBESITY Preventing and managing the global epidemic: report of a WHO Consultation on Obesity. Geneva: WHO. 1998.

[23] Grundy SM, Cleeman JI, Daniels SR, Donato KA, Eckel RH, Franklin BA, et al. Diagnosis and management of the metabolic syndrome: an American Heart Association/National Heart, Lung, and Blood Institute Scientific Statement. Circulation. 2005; 112 (17): 2735-52.

[24] Malachias M, Plavnik FL, Machado CA, Malta D, Scala LCN, Fuchs S. 7th Brazilian Guideline of Arterial Hypertension: Chapter 1 - Concept, Epidemiology and Primary Prevention. Arq Bras Cardiol. 2016; 107 (3 Suppl 3): 1-6.
[25] Third Report of the National Cholesterol Education Program (NCEP) Expert Panel on Detection, Evaluation, and Treatment of High Blood Cholesterol in Adults (Adult Treatment Panel III) Final Report. Circulation. 2002; 106: 3143.

[26] Church TS, Thomas DM, Tudor-Locke C, Katzmarzyk PT, Earnest CP, Rodarte RQ, et al. Trends over 5 decades in U.S. occupation-related physical activity and their associations with obesity. PLoS One. 2011; 6 (5): e19657.

[27] Johnson BL, Nelson JK. Practical measurements for evaluation in physical education. 3rd edition ed. Edina: Burgess Publishing1979.

[28] Baumgartner TA, Jackson AS. Measurement for evaluation in physical education and exercise science. 8th Edition ed1995.

[29] Balke B, Ware RW. An experimental study of physical fitness of Air Force personnel. US Armed Forces Med J. 1959; 10 (6): 675-88.

[30] American Heart Association (AHA). Exercise testing and training of apparently healthy individuals. A handbook for physicians. Circulation. 1972.

[31] Lakka TA, Laaksonen DE, Lakka HM, Mannikko N, Niskanen LK, Rauramaa R, et al. Sedentary lifestyle, poor cardiorespiratory fitness, and the metabolic syndrome. Med Sci Sports Exerc. 2003; 35 (8): 1279-86.

[32] LaMonte MJ, Barlow CE, Jurca R, Kampert JB, Church TS, Blair SN. Cardiorespiratory fitness is inversely associated with the incidence of metabolic syndrome: a prospective study of men and women. Circulation. 2005; 112 (4): 505-12.

[33] Farrell SW, Cheng YJ, Blair SN. Prevalence of the metabolic syndrome across cardiorespiratory fitness levels in women. Obes Res. 2004; 12 (5): 824-30.

[34] Wannamethee SG, Shaper AG, Alberti KG. Physical activity, metabolic factors, and the incidence of coronary heart disease and type 2 diabetes. Arch Intern Med. 2000; 160 (14): 210816.

[35] Roberts CK, Hevener AL, Barnard RJ. Metabolic syndrome and insulin resistance: underlying causes and modification by exercise training. Compr Physiol. 2013; 3 (1): 1-58.

[36] Pereira LE, Michelin E, Corrente JE, Burini RC. Determinants of Low Physical Activity in a Brazilian Community. In: ACSM Annual Meeting; San Diego, CA: Medicine and Science in Sports and Exercise; 2015. p. 242.

[37] Nakagaki MS, Michelin E, Burini RC. The Effects of A Lifestyle Modification Program on a Leisure Physical Activity and Sedentary Behavior in a Brazilian Low Socioeconomic Community. Journal of Sports Science. 2017; 5: 107-12.

[38] McLellan KCP, Ramos FMM, Corrente JE, Sloan LA, Burini RC. Evolutionary Roles of Dietary Fiber in Succeeding Metabolic Syndrome (Mets) and its Responses to a Lifestyle Modification Program: A Brazilian Community-based Study. Dietary Fiber: Production Challenges, Food Sources and Health Benefits. 2015: 1ed. New York: Nova Science Publishers; 2015. p. 1-7.

[39] Takahashi MM, de Oliveira EP, de Carvalho AL, de Souza Dantas LA, Burini FH, Portero-McLellan KC, et al. Metabolic syndrome and dietary components are associated with coronary artery disease risk score in free-living adults: a crosssectional study. Diabetol Metab Syndr. 2011; 3: 7. 
[40] Ramos FMM, McLellan KCP, Corrente JE, Burini RC. Determinants of the low dietary fiber intake and relationship with Metabolic Syndrome: a Brazilian community-based study. In: Experimental Biology; Boston, MA: The Faseb Journal; 2015. p. 588.15 .

[41] Ilanne-Parikka P, Laaksonen DE, Eriksson JG, Lakka TA, Lindstr J, Peltonen M, et al. Leisure-time physical activity and the metabolic syndrome in the Finnish diabetes prevention study. Diabetes Care. 2010; 33 (7): 1610-7.

[42] Anderssen SA, Carroll S, Urdal P, Holme I. Combined diet and exercise intervention reverses the metabolic syndrome in middle-aged males: results from the Oslo Diet and Exercise Study. Scand J Med Sci Sports. 2007; 17 (6): 687-95.

[43] Okura T, Nakata Y, Ohkawara K, Numao S, Katayama Y, Matsuo T, et al. Effects of aerobic exercise on metabolic syndrome improvement in response to weight reduction. Obesity (Silver Spring). 2007; 15 (10): 2478-84.

[44] Orchard TJ, Temprosa M, Goldberg R, Haffner S, Ratner R, Marcovina $\mathrm{S}$, et al. The effect of metformin and intensive lifestyle intervention on the metabolic syndrome: the Diabetes Prevention Program randomized trial. Ann Intern Med. 2005; 142 (8): 611-9.

[45] Ilanne-Parikka P, Eriksson JG, Lindstrom J, Peltonen M, Aunola S, Hamalainen $\mathrm{H}$, et al. Effect of lifestyle intervention on the occurrence of metabolic syndrome and its components in the Finnish Diabetes Prevention Study. Diabetes Care. 2008; 31 (4): 805-7.

[46] Camhi SM, Stefanick ML, Katzmarzyk PT, Young DR. Metabolic syndrome and changes in body fat from a low-fat diet and/or exercise randomized controlled trial. Obesity (Silver Spring). 2010; 18 (3): 548-54.

[47] Roberts CK, Ng C, Hama S, Eliseo AJ, Barnard RJ. Effect of a short-term diet and exercise intervention on inflammatory/anti-inflammatory properties of HDL in overweight/obese men with cardiovascular risk factors. J Appl Physiol (1985). 2006; 101 (6): 1727-32.

[48] Portero-McLellan KC, Pimentel GD, Corrente JE, Burini RC. Association of fat intake and socioeconomic status on anthropometric measurements of adults. Cad Saude Colet. 2010; 18 (2): 266-74

[49] Sasayama K, Ochi E, Adachi M. Importance of both fatness and aerobic fitness on metabolic syndrome risk in Japanese children. PLoS One. 2015; 10 (5): e0127400.

[50] Schjerve IE, Tyldum GA, Tjonna AE, Stolen T, Loennechen JP, Hansen HE, et al. Both aerobic endurance and strength training programmes improve cardiovascular health in obese adults. Clin Sci (Lond). 2008; 115 (9): 283-93.

[51] Tjonna AE, Lee SJ, Rognmo O, Stolen TO, Bye A, Haram $\mathrm{PM}$, et al. Aerobic interval training versus continuous moderate exercise as a treatment for the metabolic syndrome: a pilot study. Circulation. 2008; 118 (4): 346-54.

[52] Iellamo F, Manzi V, Caminiti G, Vitale C, Castagna C, Massaro $\mathrm{M}$, et al. Matched dose interval and continuous exercise training induce similar cardiorespiratory and metabolic adaptations in patients with heart failure. Int $\mathrm{J}$ Cardiol. 2013; 167 (6): 2561-5.

[53] Boutcher SH. High-intensity intermittent exercise and fat loss. J Obes. 2011; 2011: 868305.
[54] Gillen JB, Percival ME, Ludzki A, Tarnopolsky MA, Gibala MJ. Interval training in the fed or fasted state improves body composition and muscle oxidative capacity in overweight women. Obesity (Silver Spring). 2013; 21 (11): 2249-55.

[55] Chang KV, Hung CY, Li CM, Lin YH, Wang TG, Tsai KS, et al. Reduced flexibility associated with metabolic syndrome in community-dwelling elders. PLoS One. 2015; 10 (1): e0117167.

[56] Whaley MH, Kampert JB, Kohl HW, 3rd, Blair SN. Physical fitness and clustering of risk factors associated with the metabolic syndrome. Med Sci Sports Exerc. 1999; 31 (2): 287-93.

[57] Katzmarzyk PT, Leon AS, Wilmore JH, Skinner JS, Rao DC, Rankinen $\mathrm{T}$, et al. Targeting the metabolic syndrome with exercise: evidence from the HERITAGE Family Study. Med Sci Sports Exerc. 2003; 35 (10): 1703-9.

[58] Cornelissen VA, Smart NA. Exercise training for blood pressure: a systematic review and meta-analysis. J Am Heart Assoc. 2013; 2 (1): e004473.

[59] Duncan GE, Perri MG, Theriaque DW, Hutson AD, Eckel RH, Stacpoole PW. Exercise training, without weight loss, increases insulin sensitivity and postheparin plasma lipase activity in previously sedentary adults. Diabetes Care. 2003; 26 (3): 557-62.

[60] Dela F, Mikines KJ, von Linstow M, Secher NH, Galbo H. Effect of training on insulin-mediated glucose uptake in human muscle. Am J Physiol. 1992; 263 (6 Pt 1): E1134-43.

[61] Houmard JA, Shinebarger MH, Dolan PL, Leggett-Frazier N, Bruner RK, McCammon MR, et al. Exercise training increases GLUT-4 protein concentration in previously sedentary middle-aged men. Am J Physiol. 1993; 264 (6 Pt 1): E896901.

[62] Evans EM, Van Pelt RE, Binder EF, Williams DB, Ehsani AA, Kohrt WM. Effects of HRT and exercise training on insulin action, glucose tolerance, and body composition in older women. J Appl Physiol (1985). 2001; 90 (6): 2033-40.

[63] Yfanti C, Nielsen AR, Akerstrom T, Nielsen S, Rose AJ, Richter EA, et al. Effect of antioxidant supplementation on insulin sensitivity in response to endurance exercise training. Am J Physiol Endocrinol Metab. 2011; 300 (5): E761-70.

[64] Houmard JA, Tyndall GL, Midyette JB, Hickey MS, Dolan PL, Gavigan KE, et al. Effect of reduced training and training cessation on insulin action and muscle GLUT-4. J Appl Physiol (1985). 1996; 81 (3): 1162-8.

[65] DiPietro L, Dziura J, Yeckel CW, Neufer PD. Exercise and improved insulin sensitivity in older women: evidence of the enduring benefits of higher intensity training. J Appl Physiol (1985). 2006; 100 (1): 142-9.

[66] Barwell ND, Malkova D, Moran CN, Cleland SJ, Packard CJ, Zammit VA, et al. Exercise training has greater effects on insulin sensitivity in daughters of patients with type 2 diabetes than in women with no family history of diabetes. Diabetologia. 2008; 51 (10): 1912-9.

[67] Ostergard T, Andersen JL, Nyholm B, Lund S, Nair KS, Saltin $B$, et al. Impact of exercise training on insulin sensitivity, physical fitness, and muscle oxidative capacity in first-degree relatives of type 2 diabetic patients. Am J Physiol Endocrinol Metab. 2006; 290 (5): E998-1005. 
[68] Perseghin G, Price TB, Petersen KF, Roden M, Cline GW, Gerow K, et al. Increased glucose transport-phosphorylation and muscle glycogen synthesis after exercise training in insulin-resistant subjects. N Engl J Med. 1996; 335 (18): 1357-62.

[69] Dela F, Larsen JJ, Mikines KJ, Ploug T, Petersen LN, Galbo $\mathrm{H}$. Insulin-stimulated muscle glucose clearance in patients with NIDDM. Effects of one-legged physical training. Diabetes. 1995; 44 (9): 1010-20.

[70] Atlantis E, Martin SA, Haren MT, Taylor AW, Wittert GA, Members of the Florey Adelaide Male Ageing S. Inverse associations between muscle mass, strength, and the metabolic syndrome. Metabolism. 2009; 58 (7): 1013-22.

[71] Jurca R, Lamonte MJ, Church TS, Earnest CP, Fitzgerald SJ, Barlow CE, et al. Associations of muscle strength and fitness with metabolic syndrome in men. Med Sci Sports Exerc. 2004; 36 (8): 1301-7.

[72] Tomeleri CM, Souza MF, Burini RC, Cavaglieri CR, Ribeiro AS, Antunes M, et al. Resistance training reduces metabolic syndrome and inflammatory markers in older women: A randomized controlled trial. J Diabetes. 2017.

[73] Conceicao MS, Bonganha V, Vechin FC, Berton RP, Lixandrao ME, Nogueira FR, et al. Sixteen weeks of resistance training can decrease the risk of metabolic syndrome in healthy postmenopausal women. Clin Interv Aging. 2013; 8: 1221-8.

[74] Lemes IR, Ferreira PH, Linares SN, Machado AF, Pastre CM, Netto JJ. Resistance training reduces systolic blood pressure in metabolic syndrome: a systematic review and meta-analysis of randomised controlled trials. Br J Sports Med. 2016.
[75] Kemmler W, Von Stengel S, Engelke K, Kalender WA. Exercise decreases the risk of metabolic syndrome in elderly females. Med Sci Sports Exerc. 2009; 41 (2): 297-305.

[76] Stewart KJ, Bacher AC, Turner K, Lim JG, Hees PS, Shapiro $\mathrm{EP}$, et al. Exercise and risk factors associated with metabolic syndrome in older adults. Am J Prev Med. 2005; 28 (1): 9-18.

[77] Mota JF, Moreto F, Burini FHP, Medina WL, Rimm EB, Burini RC. Effect of physical conditioning with lifestyle intervention on a community-based hyperglycemicoverweight adults. Journal of US-China Medical Science. 2011; 8: 581-87.

[78] Burini RC, Torezan GA, McLellan KCP. Behavioral risk factors and effects of lifestyle modification on adults with diabetes. A Brazilian community-based study.. Emerging Issues in Medical Diagnosis and Treatment. 2013; 4: 1-20.

[79] Kano HT, Manda RM, Vilches GN, Burini RC. Behavioral Markers Of Hypertriglyceridemia And Determinants Of Its Normalization By A Lifestyle Modification Program. In: 63 ACSM Annual Meeting; Boston, MA: Medicine and Science in Sports and Exercise; 2016. p. 74.

[80] Kano HT, Manda RM, Moreto F, Burini FHP, Burini RC. Determinants of high plasma triglyceride levels: a Brazilian community-based study. In: Experimental Biology; Boston, MA: The Faseb Journal; 2015. p. 588.1.

[81] Burini RC, Kano HT, Nakagaki MS, Nunes CNM, Burini FHP. The lifestyle modification effectiveness in reducing Hypertension in a Brazilian Community: From the epigenetic basis of Ancestral Survival to the Contemporary Lifestyle and Public Health Initiatives. Heighpubs J Clin Hypertens. 2017; 1: 10-31. 